\title{
Nitric Oxide Synthase Activity in Human Thyroid Papillary Carcinomas
}

\author{
Eiji Takeuchi $^{1}$, Hiroya Kitano ${ }^{1}$, Hideyuki Fujioka ${ }^{2}$, Noboru Toda ${ }^{2}$, \\ Kazutomo Kitajima ${ }^{1}$ and Tomio Okamura ${ }^{2}$ \\ ${ }^{1}$ Department of Otolaryngology, Head and Neck Surgery and ${ }^{2}$ Department of Pharmacology, Shiga University of \\ Medical Science, Shiga 520-2192
}

Received January 17, 2001; accepted April 12, 2001

\begin{abstract}
In human thyroid carcinoma, there is no evidence that the activity of NO synthase and the contribution of endothelial NOS (eNOS) have been determined. To determine the relationship between NOS and human thyroid carcinomas, we assayed eNOS expression and assessed the activity of NOS in thyroid papillary carcinomas (TPC), benign thyroid tumors, and normal thyroid tissues. We investigated the involvement of NO in TPC using an assay system to measure NOS activity by high performance liquid chromatography (HPLC), which could be applied to determine citrulline enrichment. The TPC showed high levels of NOS activity. Moreover, histochemical staining with

NADPH-diaphorase revealed a positive reaction in the TPC samples, localized to the blood vessel endothelium. These cells were much less stained, however, in normal thyroid tissue. When we incubated these samples with an anti-eNOS antibody, we observed staining of the TPC samples, again localized to the blood vessel endothelium cells, but much less than in the normal thyroid samples. RT-PCR amplification using eNOS specific primers revealed that eNOS mRNA was abundant in the TPC samples, but was much less expressed in normal thyroid. These results show that NOS activity exists in TPC and that it is associated with malignancy.
\end{abstract}

Key words: HPLC, eNOS, iNOS, Thyroid, Papillary carcinoma

\section{Introduction}

Nitric oxide synthase (NOS) is an enzyme that synthesizes nitric oxide in cells. Three isoforms of this enzyme, neural (nNOS), endothelial (eNOS) and macrophage (mNOS), have been cloned and sequenced. Functionally, it has been shown that the first two isoforms are a constitutive (cNOS) type and the last one is an inducible (iNOS) type. Nitric oxide (NO) may be involved in the endogenous formation of carcinogenic nitrosamines, as well as in the deamination of DNA nucleobases [13]. NO has also been shown to be related to angiogenesis, which occurs not only during the reproductive cycle and wound healing, but also during tumorgenesis [14]. Excess NO produced in inflamed tissues may play an additional role in carcinogenesis by impairing the tumor suppressor function of p53 [3]. ENOS is expressed in human thyroid tissues. The endothelial localization of eNOS is consistent with the role of NO in the vascular con-

Correspondence to: Eiji Takeuchi, M. D., Department of Otolaryngology, Head \& Neck Surgery, Shiga University of Medical Science, Seta, Ohtsu, Shiga 520-2192, Japan. trol of the thyroid. ENOS expression in thyroid follicular cells and the variations in its immunoreactivity suggest a possible role for NO in thyrocyte function and/or growth [5, $6,16]$. INOS is present in monocytes from patients with Graves' disease [11]. Several reports in animals suggest a tumoricidal role for NO, but in human tumors its role has not been well-established. We reported previously that iNOS was expressed in the human thyroid papillary carcinoma, and also that iNOS was mostly derived from tumor cells rather than macrophages using the RT-PCR method and the immunohistochemical method [9]. In the present study, we assayed eNOS expression and compared the activity of NO synthase in human thyroid papillary carcinomas, benign thyroid tumors, and normal thyroid tissues to determine whether any relationship exists between NO and carcinogenesis in the human thyroid.

\section{Materials and Methods}

\section{Tissues specimens}

Human thyroid papillary carcinomas (TPC) were obtained at the time of surgery from 5 patients. Samples 
Table 1. Study subjects.

\begin{tabular}{cccc}
\hline Case & age & sex & tumor type \\
\hline 1 & 43 & $\mathrm{~F}$ & papillary carcinoma \\
2 & 55 & $\mathrm{~F}$ & papillary carcinoma \\
3 & 59 & $\mathrm{~F}$ & papillary carcinoma \\
4 & 66 & $\mathrm{~F}$ & papillary carcinoma \\
5 & 69 & $\mathrm{M}$ & papillary carcinoma \\
6 & 69 & $\mathrm{~F}$ & follicular adenoma \\
7 & 61 & $\mathrm{~F}$ & follicular adenoma \\
8 & 51 & $\mathrm{~F}$ & follicular adenoma \\
9 & 46 & $\mathrm{M}$ & follicular adenoma \\
10 & 68 & $\mathrm{~F}$ & adenomatous goiter \\
\hline
\end{tabular}

did not include necrotic tissue. Benign thyroid tumors were obtained from 4 cases of follicular adenoma and a case of adenomatous goiter patients (Table 1). Five normal thyroid glands from the adjacent tissue to the tumor tissue were treated as a control group. A part of the sample was placed immediately into the cold medium and prepared for subsequent assay for NO synthase activity. The rest of the sample was frozen in liquid nitrogen as soon as possible and stored at $-80^{\circ} \mathrm{C}$ for subsequent analysis.

\section{Assay of NOS activity}

In order to assess NOS activity of a tissue, we measured the citrulline amount in the tissue. Tissues were incubated in $5 \mathrm{ml}$ of Ringer-Locke solution with or without $0.1 \mathrm{mM} \mathrm{L}-$ NA maintained at $37 \pm 0.3^{\circ} \mathrm{C}$ and aerated with a mixture of $95 \% \mathrm{O}_{2}$ and $5 \% \mathrm{CO}_{2}$. Constituents of the solution were as follows: $120 \mathrm{mM} \mathrm{NaCl}, 5.5 \mathrm{mM} \mathrm{KCl}, 2.2 \mathrm{mM} \mathrm{CaCl}_{2}, 1.0$ $\mathrm{mM} \mathrm{MgCl} 2,25.0 \mathrm{mM} \mathrm{NaHCO}_{3}$ and $5.6 \mathrm{mM}$ glucose. $50 \mu \mathrm{l}$ of the bathing medium was sampled every $3 \mathrm{~min}$. The sample was deproteinized by ultrafiltration (Microcon YM-10, Amicon, Beverly, USA). The filtrate was kept in a freezer until the time of assay. O-phthalaldehyde (OPA; Nacalai Tesque, Kyoto, Japan) reagent was prepared by mixing 10 $\mathrm{mg}$ of OPA, $500 \mu \mathrm{l}$ ethanol, $9.5 \mathrm{ml}$ of $0.4 \mathrm{M}$ sodium borate buffer $\mathrm{pH} 9.5$, and $10 \mu \mathrm{l}$ of 2-mercaptoethanol. $10 \mu \mathrm{l}$ of the sample was mixed with $20 \mu \mathrm{l}$ of the OPA reagent for $60 \mathrm{sec}$. $25 \mu \mathrm{l}$ of the mixture was injected into high performance liquid chromatography system (LC-10AS, SCL-10A, C-R4A, Shimadzu, Kyoto, Japan) coupled to an octadecylsilane column $(4.6 \times 250 \mathrm{~mm}$, Nacalai Tesque, Kyoto, Japan) and a fluorescence detector (RF-10A, Shimadzu, Kyoto, Japan). The excitation and detection wave length were set to 340 and $455 \mathrm{~nm}$, respectively. The mobile phase was $0.1 \mathrm{M}$ sodium citrate buffer $\mathrm{pH} 6.0$, and a linear gradient of 25 to $85 \%$ methanol was used. The flow rate was $0.8 \mathrm{ml} / \mathrm{min}$. The difference of citrulline amount with and without L-NA in the same tissue was considered as NOS activity.

\section{NADPH-diaphorase histochemistry and eNOS immunohistochemistry}

Tissues were immersed for $2 \mathrm{hr}$ at $37^{\circ} \mathrm{C}$ in $0.1 \mathrm{M}$ phosphate-buffer saline (PBS) containing 10\% gelatin. Each specimen was cut into $5 \mu \mathrm{m}$ or $20 \mu \mathrm{m}$-sections thick. For
NADPH diaphorase histochemistry, tissue sections were washed in PBS and immersed for $1 \mathrm{hr}$ in a reagent mixture (5 $\mathrm{mg} / \mathrm{ml}$ NADPH, 5\% NBT $0.1 \%$ Triton in PBS, pH 8). For immunohistochemistry, $20 \mu \mathrm{m}$ tissue sections were washed in 0.1 M PBS-Triton solution and incubated with a 1:5000 dilution of anti-eNOS monoclonal antibody (Transduction Lab, Lexington, KY USA) for $48 \mathrm{hr}$ at $4^{\circ} \mathrm{C}$. Sections were washed thoroughly in PBS and incubated for $1 \mathrm{hr}$ with rabbit anti-mouse IgG (Vector laboratories, Burlingame, CA USA). After further washing, the sections were incubated for $1 \mathrm{hr}$ with a 1:4000 dilution of avidin-biotin-peroxidase complex (Vectatin Elete ABC Kit, Vector laboratories). Following treatment with diaminobenzidine-nickel, the sections were examined under a light microscope.

\section{Preparation of RNA and RT-PCR}

Total RNA was isolated from the TPC and normal thyroid specimens by the acid guanidium thiocyanate-phenol method [3]. Each $5 \mu \mathrm{g}$ of total RNA was treated with 10 units DNase (Pharmacia, Piscataway, NJ USA) and 20 units of RNAsin (Wako Pure Chemicals, Tokyo Japan) for $1 \mathrm{hr}$ at $37^{\circ} \mathrm{C}$ to eliminate trace DNA contamination. The DNase was inactivated by heat for $5 \mathrm{~min}$ at $95^{\circ} \mathrm{C}$ and was removed by extraction with phenol:chloroform:isoamyl alcohol (24:24:1), and the RNA was precipitated with ethanol. cDNA was synthesized from each RNA sample using 800 units reverse transcriptase (Life technologie, Frederick, MD USA) and 500 pmol of oligo-dT $12-18$ (Pharmacia). The transcriptase was subsequently heat inactivated for $10 \mathrm{~min}$ at $65^{\circ} \mathrm{C}$.

\section{PCR}

The PCR mixture for eNOS cDNA consisted of 1XPCR buffer (Takara Japan), $4.0 \mathrm{mM} \mathrm{MgCl}_{2}, 0.2 \mu \mathrm{M}$ dNTPS, 2.5 units Taq DNA Polymerase (Takara), $10 \mu \mathrm{g} / \mathrm{ml}$ cDNA template and the human eNOS cDNA primers, 5'GCCTTTGCTCGTGCCGTGGACA-3' (sense, corresponding to nt 2004-2025) and 5'-CCCTCGTGGACTTGCTGCTTTG-3' (antisense, corresponding to nt 2349-2328), which yielded a product of $346 \mathrm{bp}$. PCR was performed in an Iwaki TSR-300 thermal cycler, following, preincubation at $94^{\circ} \mathrm{C}$ for $1 \mathrm{~min}$, amplification 38 cycles (30 sec of denaturation at $93^{\circ} \mathrm{C}, 40 \mathrm{sec}$ of annealing at $59^{\circ} \mathrm{C}, 1 \mathrm{~min}$ of extension at $72^{\circ} \mathrm{C}$ ), followed by a 6 min extension at $72^{\circ} \mathrm{C}$. $\beta$-actin cDNA was simultaneously amplified according to the same protocol, using the primers, 5'-TGGTGGGTATGGGTCAGAAGGACTC-3' (sense) and 5'-CATGGCTGGGGTGTTGAAGGTCTCA-3' (antisense), which yielded a product of $266 \mathrm{bp}$ [12]. A water blank was used as a negative control in all experiments.

PCR products were electrophoresed in $1 \%$ NuSieve/1\% Seakem (FMC Products, Rockland, ME USA). DNA bands were cut out and the DNA in each band was eluted from the gel using a Gene Clean II kit (Bio 101, Vista, CA USA) followed by ethanol precipitation. The DNA was cloned into the PCR II (Invitrogen, Carlsbad, CA USA) using a DNA ligation kit (Invitrogen). The resulting plasmid was used to 


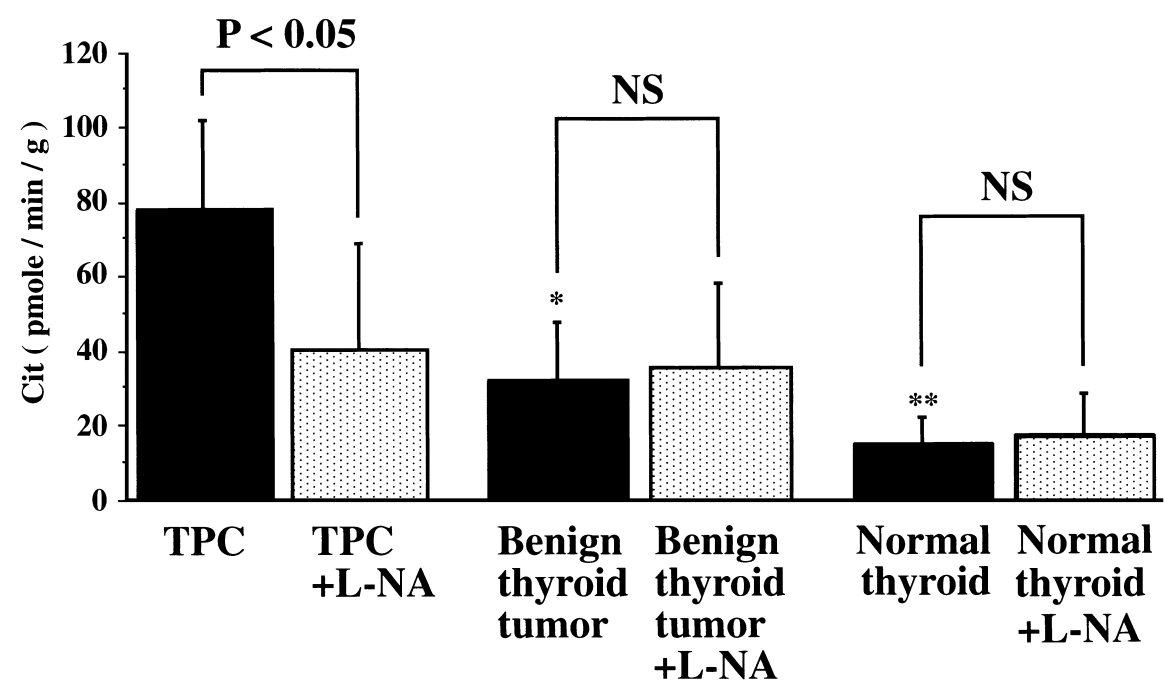

Fig. 1. Citrulline contents in human thyroid. NO synthase activity was determined by a difference of citrulline amounts in the presence and absence of L-NA, a specific NOS inhibitor. Results are means \pm S.E. of 5 samples. Significantly different from the value with $\mathrm{TPC}, * \mathrm{P}<0.05$, $* * \mathrm{P}<0.01$. NS: not significant. TPC: thyroid papillary carcinoma, 5 cases; Benign thyroid tumor: follicular adenoma, 4 cases and adenomatous goiter, 1 case; Normal thyroid: normal thyroid, 5 cases.

transform E. coli using the heat shock method and the bacteria were grown according to standard procedures. Plasmid DNA was extracted from the bacteria by alkaline lysis, purified and applied to a DNA sequencer (A. L. F., Pharmacia).

\section{Statistical analysis}

Data are presented as mean \pm standard error of the mean (SE), and comparisons between groups were performed using Student's t test. P values less than 0.05 are considered to be significant.

\section{Results}

\section{Nitric oxide synthase activity}

Citrulline formation was increased significantly in TPC compared with that in benign thyroid tumors. Moreover, this increase was completely abolished in the presence of 0.1 mM L-NA. These results indicate that NO synthase activity is present and functioning in TPC. On the other hand, the NOS activity was not detectable in benign thyroid tumors and in normal thyroid tissues (Table 2). Citrulline formation in normal thyroid was significantly less than in TPC and benign thyroid tumor (Fig. 1).

\section{Histochemical localization of NADPH-diaphorase}

In the human normal thyroid, positive stainings indicated by a blue reaction product were observed in some follicular cells and vascular endothelial cells (Fig. 2, left). Also, the staining of NADPH-diaphorase in the endothelial cells was seen in human papillary carcinomas (Fig. 2, right), which was stronger than that in normal tissues.

\section{Immunohistochemical detection of eNOS}

Incubation of normal thyroid and TPC samples with an anti-eNOS monoclonal antibody revealed a positive immu- nohistochemical reaction, indicated by the presence of a blue reaction product in the TPC samples. This staining was localized to the endothelial cells of the blood vessels (Fig. 3, right). In the normal thyroid, positive stainings were observed in the endothelial cells of blood vessels (Fig. 3, left), but they were much less compared to cells of tumor tissues.

\section{RT-PCR detection of eNOS mRNA}

When we utilized human eNOS primers to amplify sequences in human TPC cDNA, we observed a band of the expected size, as well as two additional bands (Fig. 4). Cloning and sequencing of the PCR products showed that the 346 bp band correspond to eNOS mRNA, whereas the additional bands correspond to human vimentin mRNA and human

Table 2. Citrulline content in thyroid tissue.

\begin{tabular}{cccc}
\hline & & \multicolumn{2}{c}{ Citrulline $(\mathrm{pmole} / \mathrm{min} / \mathrm{g})$} \\
\cline { 3 - 4 } Case & umor type & L-NA $(-)$ & L-NA $(+)$ \\
\hline 1 & papillary carcinoma & 96.3 & 90 \\
2 & papillary carcinoma & 38.7 & 35 \\
3 & papillary carcinoma & 83.6 & 24.6 \\
4 & papillary carcinoma & 74.4 & 20.7 \\
5 & papillary carcinoma & 96.6 & 34.3 \\
\hline 6 & follicular adenoma & 5.7 & 7.7 \\
7 & follicular adenoma & 35.6 & 32.7 \\
8 & follicular adenoma & 36.1 & 43.4 \\
9 & follicular adenoma & 42.3 & 34.9 \\
10 & adenomatous goiter & 47.2 & 42.9 \\
\hline 11 & normal thyroid & 19.9 & 14.8 \\
12 & normal thyroid & 9.9 & 10.9 \\
13 & normal thyroid & 16.4 & 16.6 \\
14 & normal thyroid & 16.8 & 21.1 \\
15 & normal thyroid & 4.6 & 7.8 \\
\hline
\end{tabular}




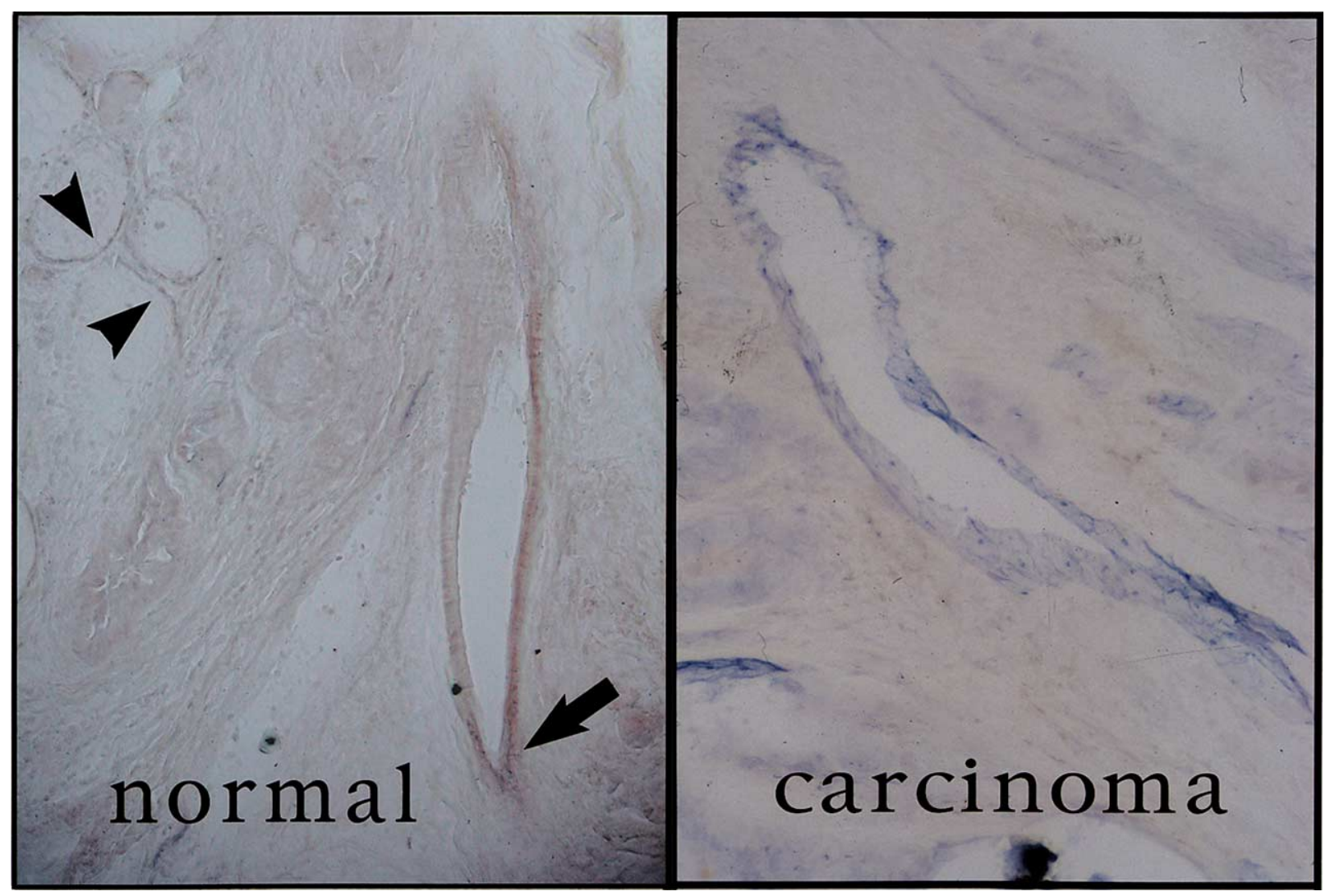

Fig. 2

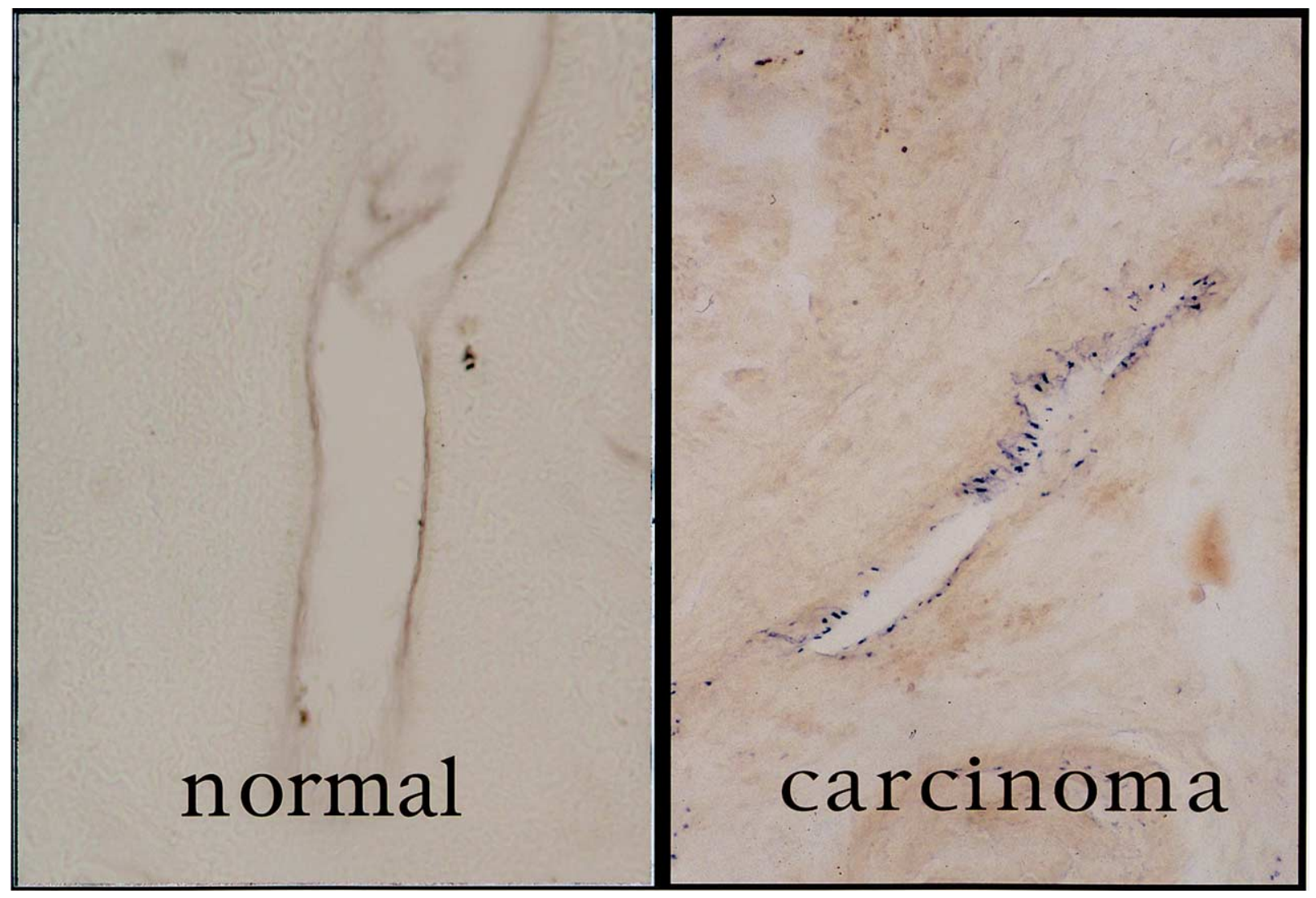

Fig. 3 


\section{$M$ normal carcinoma B}
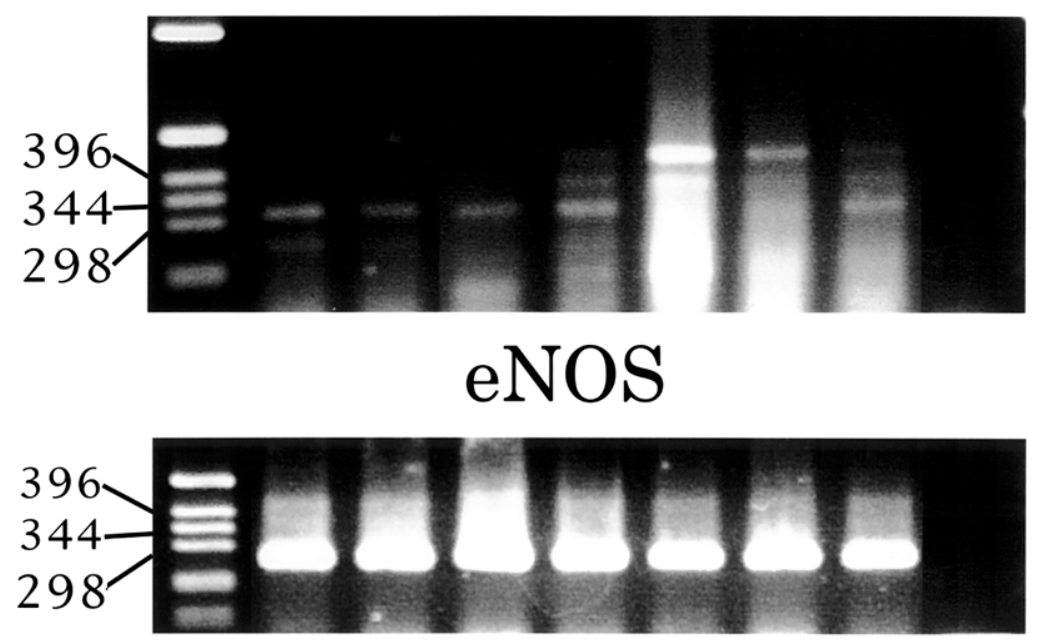

Actin

Fig. 4. RT-PCR amplification of an eNOS sequence in human thyroid samples. Primers specific for the eNOS (top panel) and $\beta$-actin genes (bottom) were used to amplify sequences in cDNA derived from thyroid carcinomas and normal thyroid tissue. Lane 1, marker DNA (M); lanes $2-4$, normal thyroid samples (normal); lanes 5-8, papillary thyroid carcinomas (carcinoma); lane 9, water blank (B).

clone 22530. All three of these bands were present in each of the four thyroid carcinoma specimens, whereas only clone 22530 was amplified in the 3 normal thyroid tissue samples (Fig. 4).

\section{Discussion}

It has been suggested that NO plays a dual role in tumor growth behavior, as an agent responsible for cellular death, or as a mediator of tumor cell proliferation [20]. NOS has been shown to have a direct role in human carcinogenesis by catalyzing the production of nitrosamines [13]. A more indirect role for this enzyme may consist of the production in infected and inflamed tissues, which may also contribute to the carcinogenic process $[1,10,13-15]$.

We investigated the involvement of nitric oxide in TPC by measuring the citrulline amount with and without a nitric oxide synthase inhibitor, L-NA. The present study showed that high levels of NOS activity were present in TPC, while the enzyme activity was not detectable in benign thyroid tumors and in normal thyroid, suggesting that NOS activity may be related to the malignancy of tumors. Basal content of citrulline in normal tissue was less than that in TPC and benign tumor. The reason is unknown, but the metabolism may be accelerated in the tumor tissue.

In our previous study, we reported that iNOS was ex- pressed in the TPC and also that iNOS was mostly derived from tumor cells rather than macrophages using the immunohistochemical and RT-PCR methods [9]. It was observed that iNOS activity, as well as NO biosynthesis, was increased in invasive cancer of the human breast and gynecological cancers compared with specimens of benign and normal tissue [18, 19]. These findings directly link iNOS tocarcinogenesis. Immunohistochemical investigations showed that in breast cancers, iNOS staining was present mainly within tumor-associated macrophages [19]. However, few tumor-associated macrophages were detected in gynecological cancers; these cells were mainly confirmed to be stroma and did not react with anti-NOS antibody [18]. In addition, iNOS was detected in epithelial cells throughout squamous cell carcinomas of the head and neck, and enzyme activity was highest in the area directly surrounding keratin pearls [2].

In the present study, the NADPH-diaphorase staining and the immunohistochemical staining for eNOS revealed a positive reaction in the TPC samples localized to vascular endothelial cells, but much less in the normal thyroid tissues. RT-PCR amplification using eNOS specific primers revealed that eNOS mRNA was abundant in the TPC samples, but much less in the normal thyroid samples. One may consider that vascular density is higher in tumor tissues than in normal tissues, but this may not be the case, because the

Fig. 2. Detection of NADPH-diaphorase in human thyroid tissues. The presence of a blue reaction denotes the enzyme. In normal thyroid, NADPH-diaphorase was expressed in some follicular cells (arrowhead) and vascular endothelial cells (arrow) (normal, $\times 50$ ). In TPC, NADPHdiaphorase was found in the vascular endothelial cells (carcinoma, $\times 50$ ).

Fig. 3. Immunohistochemical localization of eNOS in human thyroid tissues. Thyroid tissue samples were stained with a monoclonal antibody to eNOS; a positive reaction is indicated by a blue color (normal, $\times 50$; carcinoma, $\times 50$ ). 
amount of actin mRNA in the same amount of total RNA applied did not differ in both tissues. An abundant presence of eNOS in the TPC suggests another connection between NOS and carcinogenesis [1]. Since endothelial cell adhesion and vascular permeability are necessary in the early stages of metastasis, eNOS may be important in both primary growth and early stages of metastasis of human thyroid papillary carcinoma.

Vascularization is an absolute requirement for growth of solid tumors and it correlate positively with tumor metastasis. It has recently been shown that the increased tumor growth associated with iNOS-cells correlates with increased angiogenesis [7]. NO has been identified as an important regulator of tumor blood flow in experimental tumors, and inhibition of NO production in these tumors by systemically administered NOS inhibitors decreased tumor blood flow and reduced tumor growth [2,8]. It is suggested that NO production by nNOS and eNOS in tumor endothelial cells may increase tumor edema and blood supply to the tumor [4]. We provided evidence that in the TPC, iNOS was mostly derived from tumor cells and eNOS highly expressed in tumor endothelial cells. We surmise that in the TPC, iNOS is correlated with angiogenesis in tumor and eNOS is associated with vascular permeability and blood flow to the tumor. It is inferred that these two isoforms are closely related to each other in the tumor growth and metastasis. The evidence for this relationship is not clear, however, and further investigation is needed.

NOS is present in the thyroid tissues and NO may play an important role in the thyroid gland by controlling the blood flow and by directly acting on the thyroid follicular cells $[5,17]$. The distribution pattern of NO synthase activity in human thyroid, measured by our biochemical method, was almost consistent with the immunohistochemical data reported. Our work suggests that neoplastic activity in human thyroid papillary carcinoma is associated with NO production, although it cannot be determined which isoform of NOS is more associated with its activity in TPC tissues. These results also suggest that NO may have some important roles in the growth and metastasis of TPC. Further studies are necessary to investigate the effect of $\mathrm{NO}$ on malignant tumors.

\section{Acknowledgments}

Part of this research was conducted in cooperation with the department of Pharmacology and the Central Molecular Neurobiology Research Center of the Shiga University of Medical Science. This work was supported in part by a Grant-in-Aid for Scientific Research (C08671961) from the Ministry of Education, Science, Sports and Culture of Japan.

\section{References}

1. Andrade, S. P., Hart, I. R. and Piper, P. J.: Inhibitors of nitric oxide synthase selectively reduce flow in tumour-associated neovasculature. Br. J. Pharmacol. 107; 1092-1095, 1992.
2. Buttery, L. D. K., Springall, D. R., Andrade, S. P., RiverosMoreno, V., Hart, I., Piper, P. J. and Polak, J. M.: Induction of nitric oxide synthase in the neo-vasculature of experimental tumours in mice. J. Pathol. 171; 311-319, 1993.

3. Calmels, S., Hainaut, P. and Ohshima, H.: Nitric oxide induces conformational and functional modifications of wild-type p53 tumor suppressor protein. Cancer Res. 57; 3365-3369, 1997.

4. Charles, S. C., Jay, E. B., Kenneth, D. A., David, S. B. and Mark, A. I.: Expression of nitric oxide synthase in human central nervous system tumors. Cancer Res. 55; 727-730, 1995.

5. Colin, I. M., Kopp, P., Zbaren, J., Haberli, A., Grizzle, W. E. and Jameson, J. L.: Expression of nitric oxide synthase III in human thyroid follicular cells: evidence for increased expression in hyperthyroidism. Eur. J. Endocrinol. 136; 649-655, 1997.

6. Colin, I. M., Nava, E., Toussaint, D., Maiter, D. M., vanDenhove, M. F., Luscher, T. F., Ketelslegers, J. M., Denef, J. F. and Jameson, J. L.: Expression of nitric oxide synthase isoforms in the thyroid gland: evidence for a role of nitric oxide in vascular control during goiter formation. Endocrinology 136; 5283-5290, 1995.

7. Jenkins, D. C., Charles, I. G., Thomsen, L. L., Moss, D. W., Holmes, L. S., Baylis, S. A., Rhodes, P., Westomre, K., Emson, P. C. and Moncada, S.: Roles of nitric oxide in tumor growth. Proc. Natl. Acad. Sci. U S A 92; 4392-4396, 1995.

8. Kennovin, G. D., Hirst, D. G. and Flitney, F. W.: Oral N-nitro-Larginine methyl ester (L-NAME) administration slows the growth of malignant tumors in rodents (abstract). Endothelium 1; 1, 1993.

9. Kitano, H., Kitanisi, T., Nakanisi, Y., Suzuki, M., Takeuchi, E., Yazawa, Y., Kitajima, K., Kimura, H. and Tooyama, I.: Expression of inducible nitric oxide synthaze in human thyroid papillary carcinomas. Thyroid 9; 113-117, 1999.

10. Lejeune, P., Lagadecm, P., Onierm, N., Pinard, D., Ohshima, H. and Jeannin, J. F.: Nitric oxide involvement in tumor-induced immunosuppression. J. Immunol. 152; 5077-5083, 1994.

11. Lopez-Moratalla, N., Calleja, A., Gonzalez, A., Perez-Mediavilla, L. A., Aymerich, M. S., Burrel, M. A. and Santiago, E.: Inducible nitric oxide synthase in monocytes from patients with Graves' disease. Biochem. Biophys. Res. Commun. 226; 723-729, 1996.

12. Nudel, U., Zakut, R., Shani, M., Neuman, S., Levy, Z. and Yaffe, D.: The nucleotide sequence of the rat cytoplasmic $\beta$-actin gene. Nucleic Acids Res. 11; 1759-1771, 1983.

13. Ohshima, H.: Modification of cellular substances by nitric oxide: especially from the viewpoint of carcinogenesis. CRC 12; 794800, 1993.

14. Pipili-Synetos, E., Papageorgiou, A., Sakkoula, E., Sotiropoulou, G., Fotsis, T., Karakiulakis, G. and Maragoudakis, M. E.: Inhibition of angiogenesis, tumour growth and metastasis by the NOreleasing vasodilators, isosorbide mononitrate and dinitrate. $\mathrm{Br}$. J. Pharmacol. 116; 1829-1834, 1995.

15. Rosbe, K. W., Prazma, J., Petrusz, P., Mims, W., Ball, S. S. and Weissler, M. C.: Immunohistochemical characterization of nitric oxide synthase activity in squamous cell carcinoma of the head and neck. Otolaryngol. Head Neck Surg. 113; 541-549, 1995.

16. Suzuki, K., Mori, A., Lavaroni, S., Katoh, R., Kohn, L. D. and Kawaoi, A.: Thyroglobulin: a master regulator of follicular function via transcriptional suppression of thyroid specific genes. Acta Histochem. Cytochem. 32; 111-119, 1999.

17. Syed, M. A., Leong, S. K. and Chan, A. S.: Localization of NADPH-Diaphorase reactivity in the chick and mouse thyroid gland. Thyroid 4; 475-478, 1994.

18. Thomsen, L. L., Lawton, F. G., Knowles, R. G., Beesley, J. E., Riveros-Morreno, V. and Moncada, S.: Nitric oxide shynthase activity in human gynecological cancer. Cancer Res. 54; $1352-$ 1354, 1994.

19. Thomsen, L. L., Miles, D. W., Happerfield, L., Bobrow, L. G., Knowles, R. G. and Moncada, S.: Nitric oxide synthase activity in human breast cancer. Br. J. Cancer 72; 41-44, 1995.

20. Vamvakas, S. and Schmidt, H. H.: Just say NO to cancer? J. Natl. Cancer Inst. 89; 406-407, 1997. 